\title{
Environmental Impact of Cassava Processing on Residents of Surulere Local Government Area, Oyo State, Nigeria
}

\author{
Abolade Olajoke Adigun Folasade Oyenike* Abisoye Olayemi O. Adetunji M. A. \\ Department of Urban and Regional Planning, \\ Ladoke Akintola University of Technology, P.M.B. 4000, Ogbomoso Nigeria \\ *Corresponding Author
}

\begin{abstract}
The paper assessed the impacts of cassava processing industry on the residents of Surulere Local Government Area. Random sampling was employed to administer two hundred and sixty two (262) copies of a structure questionnaire to both the operators (103) and residents (159) in the selected areas. Descriptive statistics was employed to summarize nominal variables, while chi square was used to examine variations in the in the distribution socioeconomic characteristics of operators. The quantity of waste generated was determined using weighting scale and Likert scale rating was used to rate residents perception (RPI) on impacts of cassava processing on the environment. The findings showed that female is most dominant $(81.6 \%)$ in the operation of cassava production than male. Majority of the cassava production is done in a medium scale $(59.2 \%)$, (this increases generation of more waste (i.e. cassava peels) in the study area). It was observed from the measurement that cassava tuber with larger size generates more waste $(10.50 \mathrm{~kg})$ compared to small sized cassava $(8.00 \mathrm{~kg})$. The major types of pollution perceived by the residents is land pollution (RPI 2.69) and water pollution (RPI 2.48). This implies that waste generated particularly cassava peels and effluent have high negative effect on air environment. On the health impacts majority (33\%) of the operators suffer from headache and sometimes ear and sight problems. The study recommended that Government should make adequate provision for facilities like waste packing vehicles to evacuate cassava peels from the immediate working environment. This will undoubtedly enhance effective and proper disposal of wastes. Government should also encourage employees to explore opportunity of turning waste to wealth by drying cassava peels and reselling it as livestock feeds. This will serve as additional income to operators and consequently improve their livelihood. By adopting these possible recommendations, a sanitary and sustainable environment will be achieved.
\end{abstract}

DOI: $10.7176 / \mathrm{CER} / 11-8-04$

Publication date:September $30^{\text {th }} 2019$

\section{INTRODUCTION AND BACKGROUND TO THE STUDY}

The vast environmental deterioration experienced in most countries landscape through indiscriminate use of the natural endowment and waste disposal has become a more pressing issue of environmental challenge nationwide (Nwafor, 2005). The indiscriminate disposal of waste and bye product, generated from various human activities including industries (heavy, medium, light and service industries), commercial activities, operational procedures of agriculture activities among others have continued to alter the environmental system and functionality. The effects of this malaise are evident on the various components of the environment viz: physical and social environment. These have undoubtedly led to infestation of diseases on and unhealthy living condition for man (Hassan, 2010). It is a well-established fact that man's survival on planet earth absolutely depends on the environment. Therefore, unhealthy environment leads to unhealthy human existence.

According to NEST (1991), one of the problems facing Nigerian urban centers is the issue of waste management. In recent times, there has been a phenomenal increase in the volume of solid waste generation daily (over 3,000 tons of solid waste) in most countries, this is due largely to the increasing rate of population, urbanization, industrialization and general economic growth (www.ceidenuniv.academia.edu).

Waste may be defined as any substance either in form of solid, liquid or gaseous, that remains a residue or an incidental by-product of the processing of the substance or for which no use can be found by the organism or system that produces it (Allaby, 1998). Furthermore, wastes are substances or objects discarded as worthless or unwanted, defective which has no further value to the user and should be disposed (Ekpoh, 2009). Similarly, waste is an unavoidable consequence of the need for survival, which includes, living, eating, drinking and ability to provide other necessities of life. In the process of trying to satisfy these needs, waste is generated. It is a fact that the amount of waste generated by individual has relationships with per capital consumption. Wastes can be categorized into industrial, municipal or domestic, commercial and agricultural waste (Ucheagbu, 1998). Agricultural waste comes from livestock rearing (i.e. poultry, pulding fishery etc) farming activities, processes of agricultural produce like cassava into other product among others. The waste generated from these processes includes cassava peels, fibrous materials, liquor and waste water.

Cassava processing often generates waste in large quantity and most of the time indiscriminately disposed in the environmental landscape. It was further established by (IFRAD FAO 2013) that cassava processing produces large amounts of waste and is generally considered to contribute significantly to environmental pollution. Bye 
products in form of leachate and solid waste from cassava processing, were observed to be sources of pollution and burden on natural resources. Cassava is often processed into various edible foods such as' cassava", "fufu", "lafun", (Yoruba stable food) among others or sometimes as starch. These produces ample quantity of waste ranging from cassava peels, fibrous material and liquid. These waste are majorly in form of liquid and solid and if not properly managed constitute threat to environmental components. Some forms of processing particularly, starch, cassava have developed beyond traditional methods and are water intensive yet often cited in areas of water scarcity. By its nature, processing of cassava produces large volume of effluent that is high in organic content and if not properly disposed may be displayed in form of stagnant effluent ponds from which strong foul odours emanate. Many of such constitute eyesore in form of stagnant ponds. This will undoubtedly produce offensive odour that will consequently promote spread of diseases and sometimes outbreak of epidemics. Other forms of processing, that does not require water also generate dust and particles. The visual display of these pollutants makes cassava to be perceived by local population as contributing significantly to environmental damage and water deficit. For instance, if cassava starch production unit process 100 tons of tubers per day, it may produce 47 tons of fresh by-products, which may cause environmental problems when left in the surroundings of processing plant or carelessly disposed of (Aro et al, 2010). This is the scenario in most developing countries like Nigeria, where, cassava wastes are mainly left to rot away or burnt off to create space for the accumulation of new generation of waste heaps. This consequently emits carbon dioxide, methane and produces a strong offensive smell (Adebayo, 2008, Aro et al., 2010).

Cassava peels contains high amounts of cyanogenic, glycosides, and pomace, high amounts of biodegradable organic matter which causes surface water pollution especially when stored under heavy rain or simply disposed of in surface waters (Cereda and Takahaski et al, 1996; Pandey et al, 2000). The presence of a large processor or high concentration of small processors can also cause the eutrophication of slow moving water systems, notably during the dry season (FAO, 2001). On other hand, cassava processing does not seem to affect groundwater supply, except in the immediate surroundings of processing units due to leachates filtering through the soil.

Review of literature have shown that most studies focus on the quantity and composition of waste produced by the industry, but few (Adebayo 2008, FAO 2001, Pandey et al, 2000) have considered the environmental impact of light industries in rural areas. In the light of these, this paper seeks to examine the perceived environmental impacts of wastes generated from cassava processing industries in Surulere Local Government Area that is predominately agrarian in occupational characteristics.

\section{MATERIAL AND METHODS}

This research is descriptive and analytical in nature and therefore relies on field survey. Data were collected through primary and secondary sources. Primary data involve the use of two sets of structured questionnaire, which were designed to elicit information from operators of cassava processing industries and residents in the study area that lived within the areas where cassava processing is mostly carried out. This became necessary because it is assumed that the impacts of cassava processing will be felt more by residents within close proximity to operations compared to residents residing at a farther distance from the industries. This method became justified because the population of each selected villages are not readily available.

The sample frame comprises of ten political wards in Surulere Local Government area in Ogbomoso. Although five wards that are predominantly agrarian were sampled for the study. These includes: Iresaadu, Iresaapa, Iwofin, Bayeoje, and Gambari. Inventory of all the cassava processing in each of the selected villages were obtained from the association of cassava processing industries in the study area. This is summarized and presented on Table 1. The total number of cassava processing in the selected villages is two hundred and four. However fifty percent of the operators were randomly selected for questionnaire administration in the study area. i.e. one hundred and three operators were considered for questionnaire administration using random sampling technique.

The second sets of questionnaire were administered to residents. First, there was a compilation of house numbers given to each housing unit by National Commission. A good proportion of newly built houses were numbered and included in the list. From the complied lists of 318 housing units that surrounds the processing centers, $50 \%$ of housing units were randomly selected for questionnaire administration. A mature individual not less than 18 years (who have right to vote) was chosen from a household in each of the housing unit selected to respond to question contained in the questionnaire. Notwithstanding, children were also given privilege of responding to oral questions. There was, however, exceptional cases like:

- Multi-household building (more than one household occupying only one building): The household with longest stay in the housing unit was selected.

- Multi-building single household (a single household occupying more than one building). This is a common feature of the traditional Yoruba settlements as a result of the polygamous and extended nature of Yoruba families. If two or more housing units randomly selected were of multi-building single household (i.e. Agbole), only one questionnaire was used just like any other household unit(s) from a 
complied list of housing units for the particular settlement under investigation. It is equally noteworthy to mention that there were some cases where housing units selected were empty (either unoccupied or residents not at home) such housing units were skipped.

Therefore a total number of one hundred and fifty nine residents were randomly sampled in all the selected villages in the study area. This is summarized in Table 1.

Table 1: Questionnaire Distribution among Respondents in the Selected Rural Areas

\begin{tabular}{|l|l|l|l|l|}
\hline $\begin{array}{l}\text { Selected Areas } \\
\text { for Survey }\end{array}$ & $\begin{array}{l}\text { Number of } \\
\text { operators }\end{array}$ & $\begin{array}{l}\text { Sample size (50\% of } \\
\text { operators) }\end{array}$ & $\begin{array}{l}\text { Number of } \\
\text { dwelling units }\end{array}$ & $\begin{array}{l}\text { Sample size (50\% of } \\
\text { dwelling Units) }\end{array}$ \\
\hline Iresaapa & 72 & 36 & 15 & 8 \\
\hline Iresaadu & 47 & 24 & 97 & 49 \\
\hline Bayaoje & 19 & 7 & 70 & 35 \\
\hline Iwofin & 14 & 10 & 18 & 8 \\
\hline Gambari & 52 & 26 & 118 & 59 \\
\hline Total & 204 & 103 & 318 & 159 \\
\hline
\end{tabular}

\section{Source: Field Survey, (2014)}

The quantity of cassava wastes generated from each selected area was measured using weighting scale shown on Plate 1. The instrument was positioned on the ground, a bag full of cassava tubers (not peeled) was placed on a weighing scale to determine the weight of the tubers. The quantity of waste i.e cassava peels generated from the same was determined after the peeling process. This was done for different sizes (big and small) of tubers in the selected cassava processing industries. Several constraints were encountered during the process of carrying out waste measurement. The processors were not ready to give their cassava waste for measurement and some were reluctant to give reasonable answers on how their waste is been disposed. The overall average for different sizes was determined.

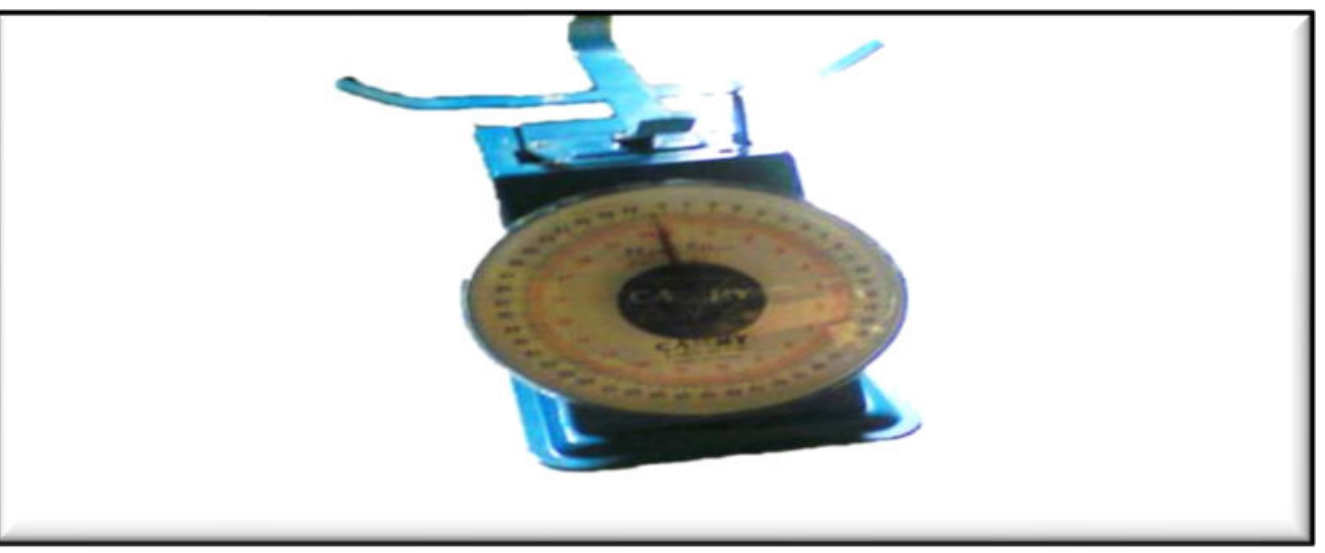

Plate 1: Weighing Scale

Descriptive statistics was employed to summarize nominal variables, while chi square was used to examine variations in the distribution of socioeconomic characteristics of operators. Likert scale rating was used to rate residents' perception on impacts of cassava processing on the environment. From this an index termed 'Resident Perception Index' (RPI) was developed. Data collected were summarized and analyzed using descriptive and inferential statistics respectively: this includes frequency, percentages and cross tabulation.

\section{RESULTS AND DISCUSSION}

\section{Scale of Cassava Production}

As shown in Figure 1, majority 59.2\% of cassava industries operate on a medium scale, although some of the cassava industries operate on a large scale production (32\%) while $8.7 \%$ operate on a small scale production. This suggests that most of the operators majorly operate on a medium scale production. This will undoubtedly enhance their living standard and will further reveal the likehood of quantity of waste generated and its associated implications on the environment. It can therefore be inferred that the larger the scale of operation, the larger the quantity of various form of waste generated and the greater its implications on the environment. 


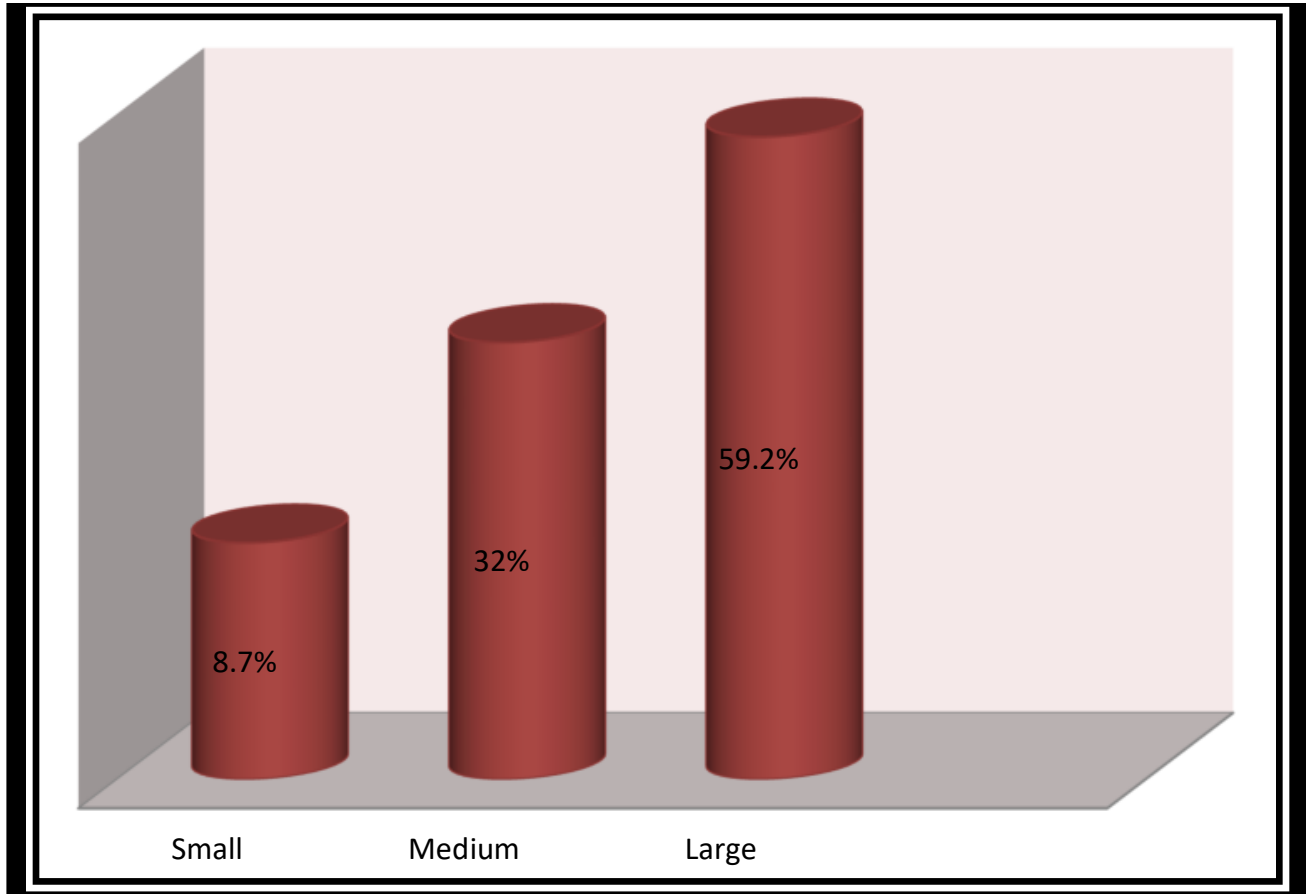

Figure 1: Level of Production of Garri Processing Industry

\section{Form of Waste Generated}

Three forms of waste are generated in garri processing industries. These include: solid waste in form of cassava peels, liquid waste like cassava waste water and particles. Documented on Figure 2 are categories of waste generated from cassava processing industries. Majority $(53.4 \%)$ of the respondents indicated that all the three categories or forms of waste are generated during garri processing but in different quantity. However, the most significant waste generated from the processing in the study area is solid waste. This constituted eyesore to the environment because they are not properly disposed and managed.

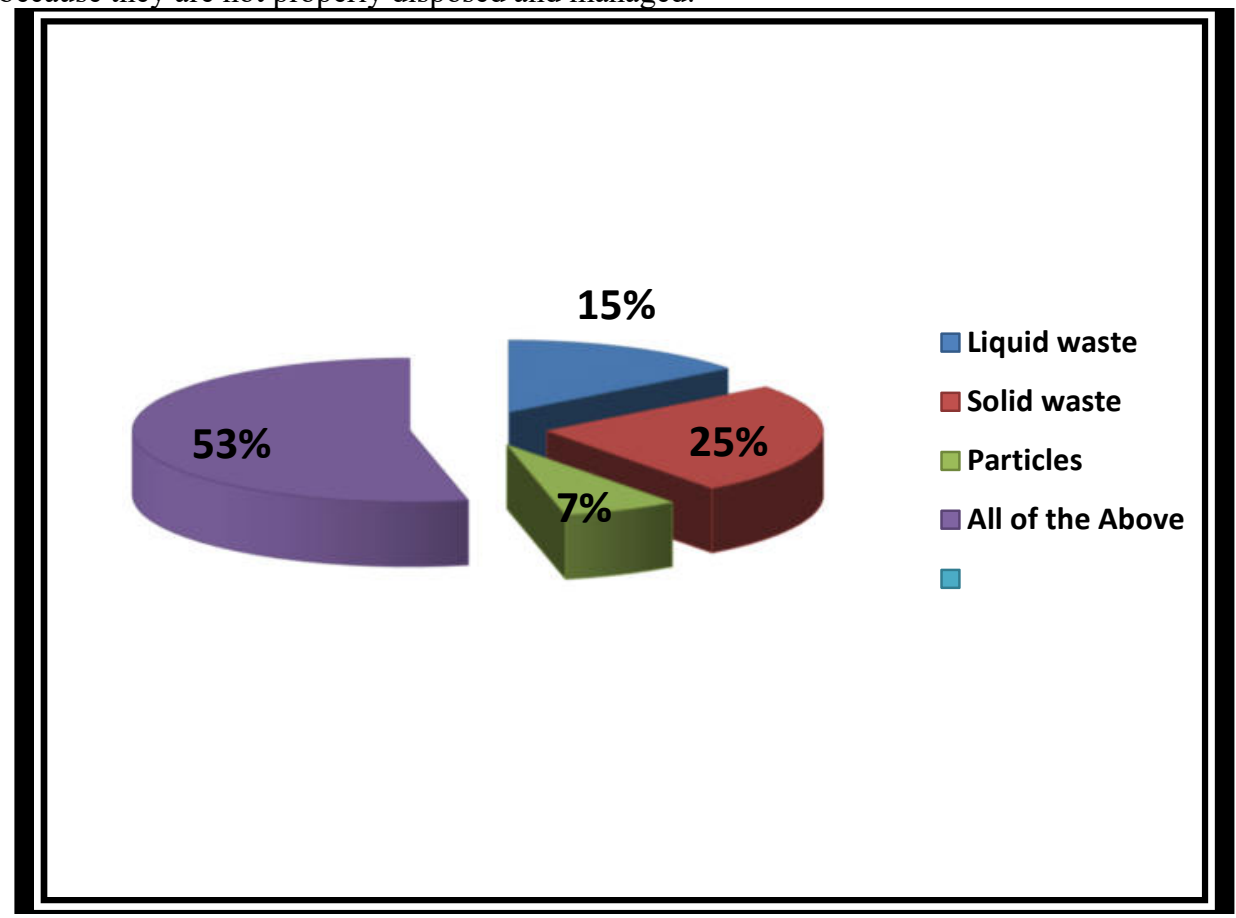

Figure 2: Form of Waste generated 
Quantity of Waste Generated

The paper examined quantity of cassava waste generated in the study area. It measured cassava peels generated from each of the selected rural areas (Iresaapa, Iresaadu, Bayeoje, Iwofin and Gambari). One cassava processing industry from each selected area was sampled for the measurement of waste generated. The measurement helped to determine the quantity of waste generated per day from sampled industries. It was observed that the more the level of production the higher the level of waste generated from the industries.

From the measurement of the cassava tubers of various sizes (i.e. big, medium or small sized tubers) and the peels generated it was deduced that the size of cassava tubers determine the quantity of cassava peels. The bigger the cassava tuber, the more the cassava peels generated and vice versa. It was observed from the results of the measurement that cassava tuber size with $26.00 \mathrm{~kg}$ and $25.50 \mathrm{~kg}$ in Iresaapa and Iresaadu generated same kilograms of waste i.e. $10.50 \mathrm{~kg}$ while the weight of waste (cassava peels) generated in Iwofin, Gambari and Bayaoje also differs slightly $8.00 \mathrm{~kg}, 9.00 \mathrm{~kg}$ and $8.00 \mathrm{~kg}$ respectively. The small sized cassava tubers also show slight variation in the quantity of cassava generated. This ranges from $9.00 \mathrm{~kg}$ to $8.00 \mathrm{~kg}$ depending on the size of cassava tuber as presented in Table 2.

Table 2: Quantity of Waste Generated

\begin{tabular}{|l|l|l|l|}
\hline \multicolumn{2}{|l|}{ Rural Areas } & $\begin{array}{l}\text { Estimated Quantity of Cassava } \\
\text { Tuber per Bag (kg) }\end{array}$ & $\begin{array}{l}\text { Estimated Quantity of } \\
\text { Cassava Peels (kg) }\end{array}$ \\
\hline \multirow{3}{*}{ Iwofin } & Big & 26.25 & 9.00 \\
\cline { 2 - 4 } & Small & 24.25 & 8.00 \\
\hline \multirow{3}{*}{ Iresaadu } & Big & 26.00 & 10.50 \\
\cline { 2 - 4 } & Small & 21.00 & 8.00 \\
\hline \multirow{2}{*}{ Iresaapa } & Big & 25.50 & 10.50 \\
\cline { 2 - 4 } & Small & 23.00 & 8.50 \\
\hline \multirow{3}{*}{ Gambari } & Big & 25.00 & 9.00 \\
\cline { 2 - 4 } & Small & 22.50 & 8.50 \\
\hline Bayaoje & Big & 24.25 & 7.50 \\
\cline { 2 - 4 } & Small & 23.26 & 8.50 \\
\hline
\end{tabular}

Source: Author's field survey, 2014

\section{Method of Waste Disposal}

Illustrated on Figure 3 and plates $2 \mathrm{a}, 2 \mathrm{~b}$ and $2 \mathrm{c}$ are the methods of waste disposal employed by the cassava processing industries. Most (37.9\%) of the industries disposed their fermented water into the gutter, and some $(28.2 \%)$ dug pits as a temporary storage, $22.3 \%$ disposed it on the bare ground while some $(10.7 \%)$ allowed it to flow directly into the rivers. The waste water that sinks into the soil by pouring it on the bare ground can be accounted for the offensive odour usually perceived in most of the area where cassava is processed. This also contributed to environmental pollution in the area.

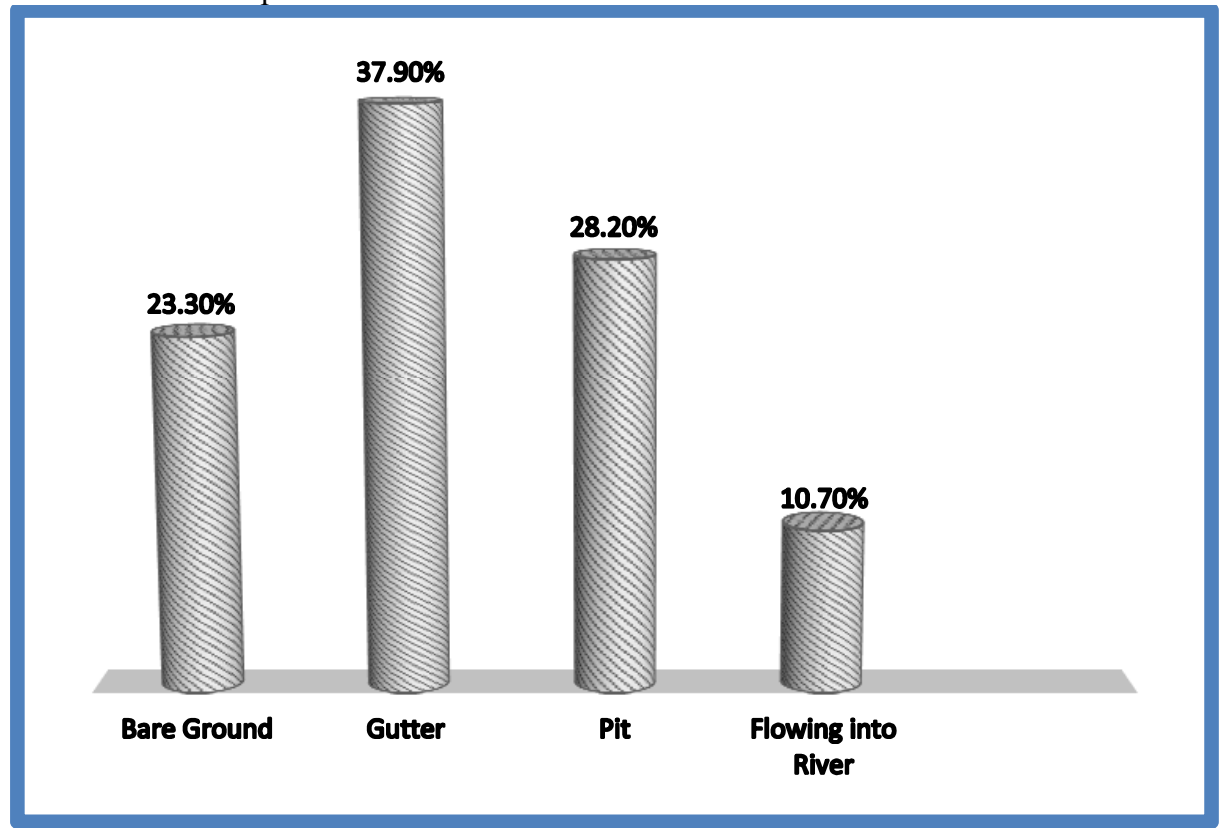

Figure 3: Waste Disposal in Garri Processing 


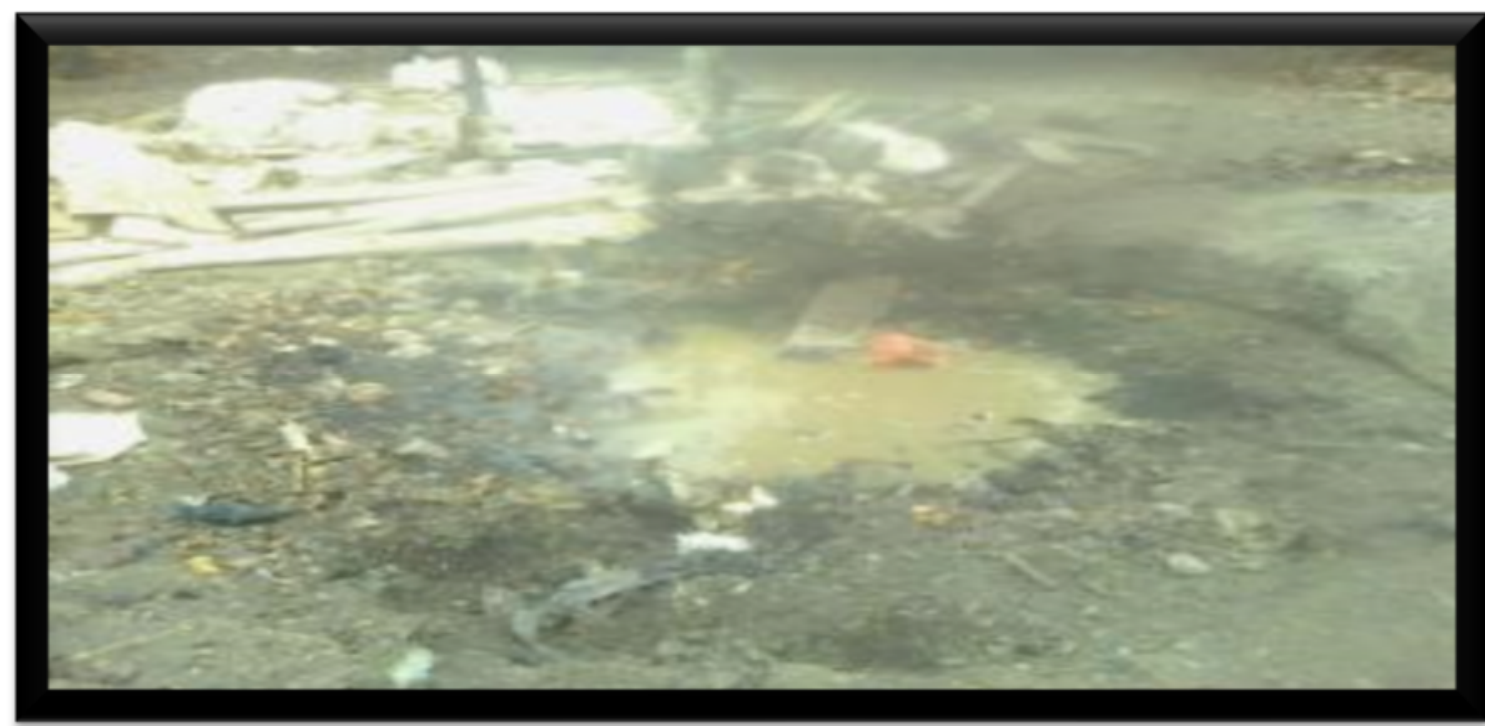

\section{Plates 2a}

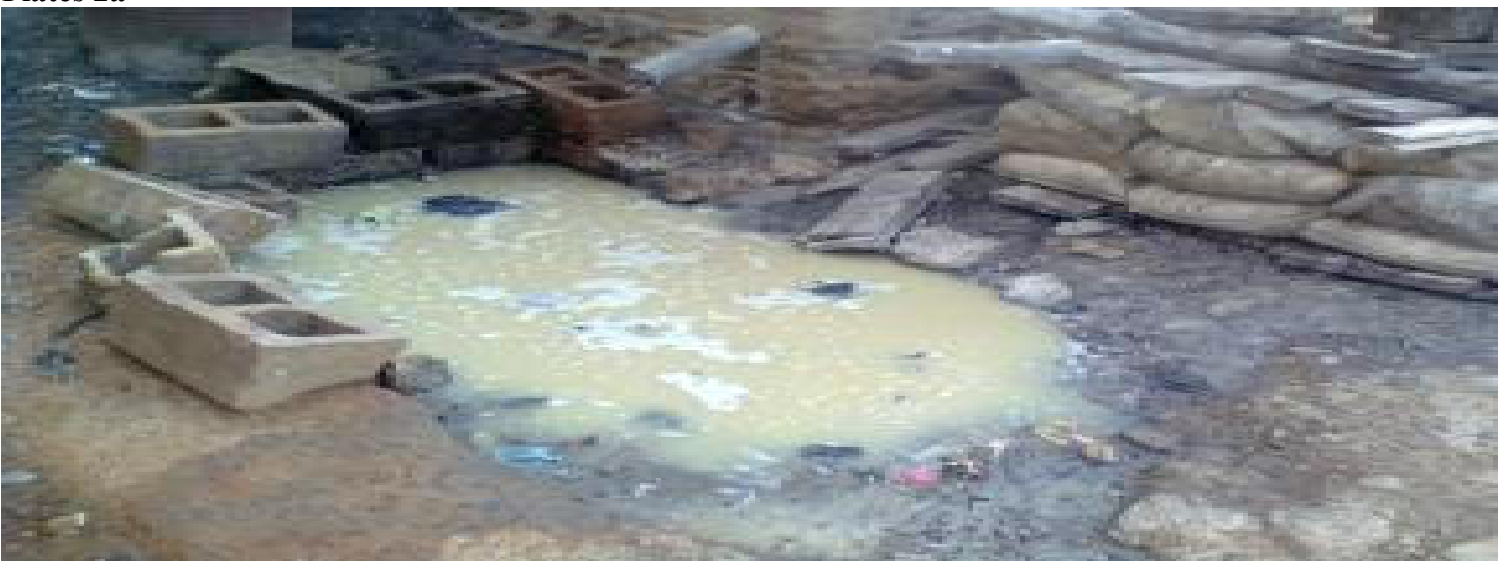

Plates 2b

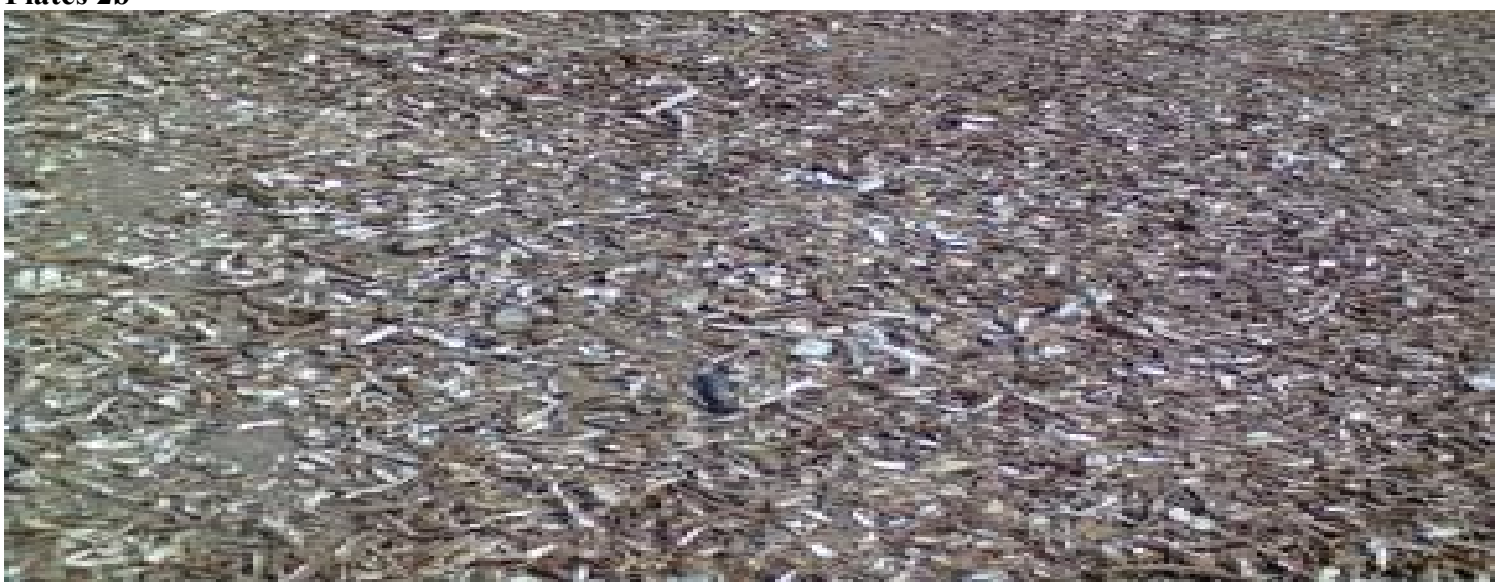

\section{Plates 2c}

Plates 2a, 2b, 2c: Methods of Waste Disposal

Perceived Health Problem of Cassava Processing

Depicted on Figure 4 are the various health problems experienced by the residents in the study area. Majority (33.3\%) of the operators suffer from headache, $23.9 \%$ suffer from cough and catarrh. The larger proportion of operators recorded for headache, cough and catarrh is a result of occupational stress attached to garri processing, stress, smoke, sieving and frying involved in the cassava processing. Other ailments reported by operators include 
sight problem (17.9\%) and ear impairment (5.7\%). The operational procedure such as sieving before frying and use of firewood as the commonly used fuel in the process of frying is the main underlying factor for these ailments.

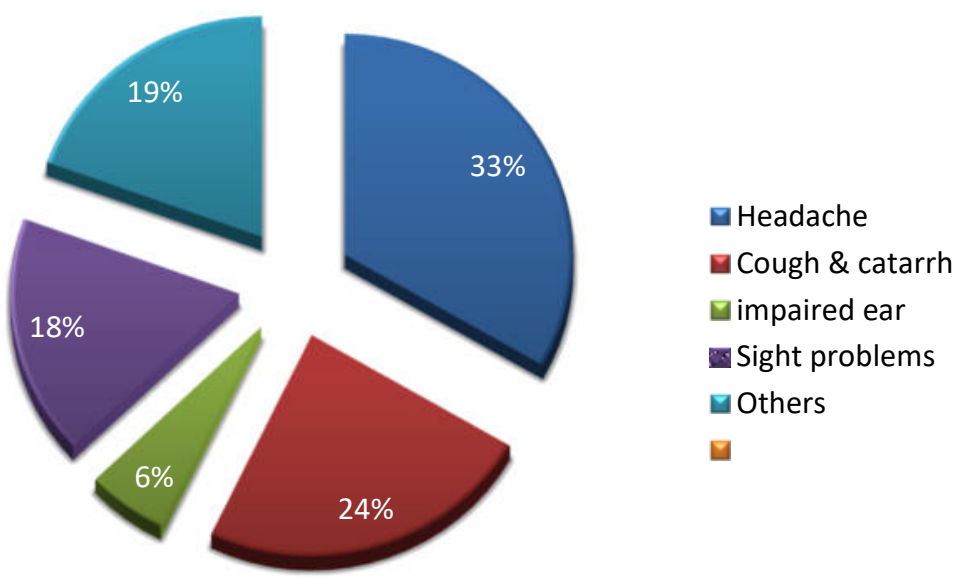

Figure 4: Health Problems Experienced by the Residents

\section{Perceived Impact of Cassava Processing on Residents and Operators}

Using Likhert scale to ascertain the validity of the effect of the cassava processing industries on the environment and the health of the workers and residents i.e. air, land and water. The respondents in the study area were classified into four groups for the calculation of Residents' Perception Index. These are rated using one of "Very Significant, Significant, Moderately Significant, Not Significant'. A weight value is attached to the four different ratings which the residents and workers used in indicating the effect

The total weight value (TWV) for each category of workers and residents were calculated by summing up the product of the weight value of the effects and the corresponding number of respondents $(\mathrm{N})$ that expressed specific effect perception. The average of the (SWV) i.e. SWV taken is the RPI. For example, if a, b, c, d are the numbers of respondents that reactively expressed that the effect is VA-Very Significant, S - Significant, MS- Moderately Significant, A-Not significant.

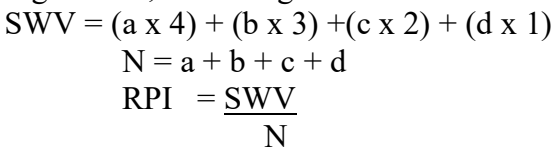

The nearest the RPI to unity scale 4, the more serious the effect of the industrial activities and waste on the health of the workers, residents, and their environment. The means of the RPI distribution was also computed. Furthermore, the deviation about mean of each variable, the variance and standard deviation of the distribution were also calculated to measure the scatter around the mean i.e. how large or small the observation fluctuate above or below the mean. When the calculated deviation is positive, it shows less or little importance of an indicator to a variable and has no serious effect on it. When the deviation is negative, it shows relevance of the indicator to the variable and shows the seriousness of the effect at the same time.

Table 3: Perceived Impact of Cassava Processing

\begin{tabular}{|l|l|l|l|l|l|l|l|l|l|}
\hline Population & VS & S & MS & NA & SWV & TOTAL & RPI & $(\mathbf{x}-\mathbf{x})$ & $(\mathbf{x}-\mathbf{x})^{\mathbf{2}}$ \\
\hline Air pollution & 50 & 90 & 19 & - & 527 & 159 & 3.31 & 0.21 & 0.1764 \\
\hline Noise pollution & 41 & 96 & 19 & 3 & 493 & 159 & 3.10 & -0.42 & 0.0441 \\
\hline Soil pollution & 33 & 56 & 50 & 20 & 420 & 159 & 2.69 & -0.21 & 0.0441 \\
\hline Water pollution & 21 & 61 & 51 & 26 & 395 & 159 & 2.48 & 0.42 & 0.1764 \\
\hline Total & & & & & & & 11.58 & & 0.441 \\
\hline
\end{tabular}

Source: Author's field survey, 2014.

VA-Very significant, S- Significant, MS- Moderately significant, A-Not significant

$\mathrm{X}=\underline{\Sigma \mathrm{RPI}}=\underline{11.58}=$ 
Variance $=\frac{\Sigma(\mathrm{x}-\mathrm{x})^{2}}{4}=\frac{0.441}{4}=0.11$

Standard Deviation $\mathrm{SD}=\sqrt{0.11}=0.33$

The study revealed that land pollution, air pollution, noise pollution, water pollution are the major type of pollution experienced in the area. This pollution has high effect on the residents with RPI value of 3.31, 3.10, 2.69 and 2.48 respectively. The major types of pollution experienced by the residents are land and water pollution with an RPI value of 2.69 and 2.48 respectively. The highest negative index shows that the level of pollution has serious effects on the residents with negative deviation of -0.42 and -0.21 respectively.

The perceived impact of cassava waste on environmental component is presented on Table 4. It was observed that cassava peels $(\mathrm{RPI}=3.40)$, waste water from cassava $(\mathrm{RPI}=3.01)$ and odour generated from the same $(\mathrm{RPI}$ $=2.99$ ) has significant impact on land. On the contrary, smoke and noise generated from cassava processing does not have major impact on land. This is evident in their RPI values which is below the mean value.

The impact of cassava processing on air quality revealed that the calculated value of RPI, for smoke, odour and noise with an RIP value of $3.33,3.17$ and 2.81 with deviation of $0.54,-0.38,0.02$ shows that it has very high negative effect on air quality. It can be observed from the findings that cassava peel and waste water have little or lesser effect on the quality of air because it recorded low RPI value when compared with the mean value.

The effect of cassava processing on water quality is also presented in Table 4 . The most significant effect of cassava processing on water quality is RPIU value of 3.18 with a negative deviation of -0.62 . Cassava peels and odour does not have serious effect on water quality. This is evident in the RPI value of 2.36 and 2.13 and positive deviation of 0.20 and 0.43 respectively.

Table 4: Categories of Waste and Perceived Impacts on Environmental Component

\begin{tabular}{|l|l|l|l|l|l|l|l|l|l|}
\hline \multirow{2}{*}{ Categories of waste } & \multicolumn{3}{|l|}{ Impact on land quality } & \multicolumn{3}{l|}{ Impact on air quality } & \multicolumn{3}{l|}{ Impact on water quality } \\
\cline { 2 - 11 } & RPI & $\mathbf{x}-\mathbf{x}$ & $\mathbf{( x - x ) ^ { \mathbf { 2 } }}$ & $\mathbf{R P I}$ & $\mathbf{x}-\mathbf{x}$ & $\mathbf{( x - x ) ^ { \mathbf { 2 } }}$ & $\mathbf{R P I}$ & $\mathbf{x}-\mathbf{x}$ & $\mathbf{( x - x}^{\mathbf{2}}$ \\
\hline Cassava peels & 3.40 & 0.46 & 0.212 & 2.13 & 0.66 & 0.436 & 3.18 & -0.62 & 0.384 \\
\hline Waste water & 3.01 & 0.07 & 0.049 & 2.53 & 0.26 & 0.068 & 2.36 & 0.20 & 0.04 \\
\hline Odour & 2.99 & 0.05 & 0.025 & 3.17 & 0.38 & 0.144 & 2.13 & 0.43 & 0.18 \\
\hline Smoke & 2.68 & 9.26 & 0.068 & 3.33 & 0.52 & 0.292 & - & - & - \\
\hline Noise & 2.62 & 0.32 & 0.102 & 2.81 & 0.02 & 0.004 & - & - & - \\
\hline Total & 14.7 & & 0.456 & 13.97 & & 0.944 & 7.67 & & 0.604 \\
\hline
\end{tabular}

Source: Author's field Survey, 2014

Conclusion and Recommendations

The processing of cassava tuber into garri is associated with diverse hazards and needs to be properly managed by adopting integrated systems of wastes management. The following are the major conclusion drawn from the study

1. There is no particular place allocated for cassava processing industries in all the selected areas.

2. Effluents from cassava discharge are not properly managed, much of the effluents are breeding space for mosquitoes, house flies, vectors or pathogens. This may serve as medium for transmission of diseases which may have serious impacts on operators and the residents in the selected areas.

3. Cassava peels are not properly disposed in all the selected areas.

Against this background, this paper recommends the followings:

1. In the design and or preparation of layout schemes for various parts of the settlement particularly the rurals where garri processing is a major preoccupation. Expansive land area should be allocated for such cottage industry.

2. There should be provision of facilities for proper disposal of effluents by operators and defaulters should be sanctioned by appropriate governmental bodies.

3. Operators should be encouraged to repackage cassava peels. This can be put for sale and further used for animal feeds, generation of energy among others

The role of government bodies and personnel (i.e. public health officials, town planning) is very important in enforcement of law, ensuring compliance of the garri processors or producers so as to achieve orderliness and to avoid future haphazard formation or springing up of processing units proliferating the landscape and constituting landuse conflicts with consequential spatial disorderliness and pollution.

1. The Government through the Local Planning Authorities should embark on relocation of some of the processing units far from residential areas where they are currently massed together within neibourhood.

2. Processing unit(s) should individually and collectively provide facilities for effective disposal of wastes from the industries. For instance, effluent discharged from cassava processing through grinding and jacking can be controlled by placing a treatment tank beneath the dug hole such that effluent from dewatering can be collected in the tank instead of the waste water flooding the processing environment. The effluent often gives foul smell during fermentation and drying process. But if this method is 
employed, it will undoubtedly reduce its effect on the air quality.

3. Non-governmental organization should collaborate with processors to provide waste packing vehicles to evacuate cassava peels from the immediate working environment. This can be enhanced by encouraging Garri processors to sun dry the cassava peels and package the dried peels in bags before evacuation by NGOs. The packaged cassava peels can be used to feed livestock and also use as manure or organic fertilizer for plant. This approach will reduce the eyesore created by heaps of cassava peels and promote liability.

4. In addition. in a new area where the industries are to be established, Government should provide immunization and vaccination at stipulated or arranged interval to garri processors to prevent spread of diseases. The use of protection wears like overall, goggles, coats, ear protective and nose masks should be made mandatory for workers of garri processing industries. The workers should also be given better orientation on how to minimize and monitor exposure to cyanide, smokes, fumes and fires. They should also be encouraged to take sufficient water because of body dehydration caused by excessive exposure of the body to heat from frying.

5. Apart from Governments established monthly environmental sanitation a day or two should be introduced in these areas for sanitation exercise so as increase the level of sanitation in the area. Sanctions should be placed on deviants or defaulters.

6. Finally, majority of the processing units clamoured for assistance from Government in provision of modern processing machine so as reduce stress of production, reduce waste generated during production to the bearest minimum level.

\section{REFERENCES}

Adebayo K. (2006): "Dynamics of Technology Adoption Process in Rural-based Cassava Processing”./ technology Adoption and Diffusion process www.unaab.edu.ng/attachment/dynami

Allaby, M. (1998): Enterobacteriaceae. A Dictionary Encyclopedia.com (http://www.encyclopedia.com)

Aro S.O. Aletor V.A. Tewe O.O and Agbede J.O (2010): "Nutritional Potentials of Cassava Tuber wastes": A Case Study of a Cassava Starch Processing Factory in South-Western Nigeria. Livestock Research for Rural Development Volume 22, Article 123

Cerada M.P. Takahaski, M (1994): "Cassava Waste Their Characterization. Uses and Treatment in Brazil". In Cassava Flour and Starches Progress in Research and Development CIAT- CGIAR International Center for Tropical Agriculture. CGIAR. P. 223

Ekpoh, I.J. (2009): Climate Society in Calabar" Saint Paul's Printing and Publishing Company

Essaghah, I.J. (2009): "Urban Planning Concepts Standards and Symbols" Lagos Amfitop Books Nig. Ltd

FAO (1994): "African Experience in the Improvement of Post-harvest Technique. Food and Agricultural organization of the United Nations, Agricultural Engineering Service (AGSE)" Support Systems Division Workshop, Held in Accra Ghana $4^{\text {th }}$ to $8^{\text {th }}$ July, Rome www.fao.org/docrep/WI544E/WI544E07.HTM

FAO and IFAD (2013). "The Global Cassava Development strategy" Cassava for livestock Feed in Sub-Saharan African www.fao.org/docrep/007/WI1125500.ht

Hassan, A. (2010): "Efficiency Inducting Taxation for Polluting Oligopolists" Journal of Public Economics, Volume 70n2, p 325-342.

Nest (1991): "Nigerian's threatened Environment" A National Profile, Ibadan, Nigeria

Nwafor, N.R. (2005): International Drug Free Athletics (IDFA), Ifa.camposnkechinwaforrobinson.gg

Pandey, S.K. Gupta and Mukharjee AK. (2000): "Impacts of Cadmium and Lead on Catharanthus Roseus-A Phytoremediation Study". Journal. Environ. Bio 1, 28,655-662

Uchegbu, S.N., (1988): “Environment Management and Protection”. Enugu Precision Printers Publishers, Enugu, Nigeria pp 15-90. 